\title{
DEPRESSOR EFFECTS OF POTASSIUM-DEFICIENT DIETS IN HYPERTENSIVE MAN ${ }^{1}$
}

\author{
By GEORGE A. PERERA \\ (From the Department of Medicine, Columbia University College of Physicians and Surgeons, \\ and the Presbyterian Hospital, New York, New York)
}

(Submitted for publication March 6, 1953 ; accepted April 1, 1953)

The relationship of the sodium ion to blood pressure levels in certain hypertensive states is now established beyond cavil. But whether alterations are mediated through the adrenal cortex, through renal or other pressor mechanisms, or through modification of neuromuscular responses at an arteriolar plane, cannot be stated at the present time.

In recent years the potassium ion has been considered in other ways than its known effects on cardiac muscle contraction or on synaptic transmission. Potassium chloride-flooding in rats has been reported to induce an increased renal and a decreased cardiac weight as well as hypertrophy of the adrenal glomerulosa zone (1). Furthermore, Freed, Friedman and Rosenman have demonstrated that dietary potassium restriction will lower the blood pressure in normal and hypertensive rats, block the pressor effects of desoxycorticosterone, and reduce peripheral vascular reactivity (2-5).

The present study was undertaken to investigate the effects of potassium-deficient diets in hypertensive man, with the hope that further light might be thrown on the mechanisms involved in sodium restriction.

\section{METHODS}

Five observations were made on four patients with hypertensive vascular disease, uncomplicated save that two had sustained relatively minor cerebral vascular accidents at least a year before. The conditions, diagnostic procedures and methods ${ }^{2}$ were similar to those reported previously (6), including the utilization of "resting" blood pressure measurements, constant dietary and fluid intakes,

1 This study was supported by grants from the Albert and Mary Lasker Foundation, the Albert $\mathbf{H}$. and Jessie $\mathbf{D}$. Wiggin Foundation, and the National Heart Institute (USPHS).

2 The author is indebted to Dr. James A. L. Mathers for ballistocardiographic studies with the low frequency, critically-damped instrument, and to Dr. K. W. Thompson of Organon, Inc., Nutley, N. J. for supplying the desoxycorticosterone acetate (DOCA). and preliminary periods of hospital supervision of about three weeks. Desoxycorticosterone acetate was administered subcutaneously in $\mathbf{5} \mathbf{~ m g}$. doses once daily.

Identical salt-poor daily menus were prepared as before (6), with sodium chloride administered by mouth from weighed salt shakers to yield a total daily intake of about 4 grams. Potassium restriction was achieved (without change in total fluids, calories, sodium or the addition of special ingredients) by almost complete elimination of fruit juices, potato, milk and eggs, reduction of meat and coffee, selection of certain fruits, cereals and vegetables, and the addition of fats, sugar and ginger ale. This resulted in a decreased protein intake (ranging in different patients from 69 to 84 grams per day in the control period, to 31 to 48 grams while on the curtailed regimen) and an increase in the consumption of fat. Repeated direct analyses of aliquots taken from an entire day's cooked diet confirmed the constancy of the regimen.

\section{RESULTS}

Tabular representation of the results is summarized in Table I and an illustrative case record is shown in Figure 1. The restriction of potassium, to approximately a third or a quarter of normal intake, was associated with a small but consistent and statistically significant decrease in

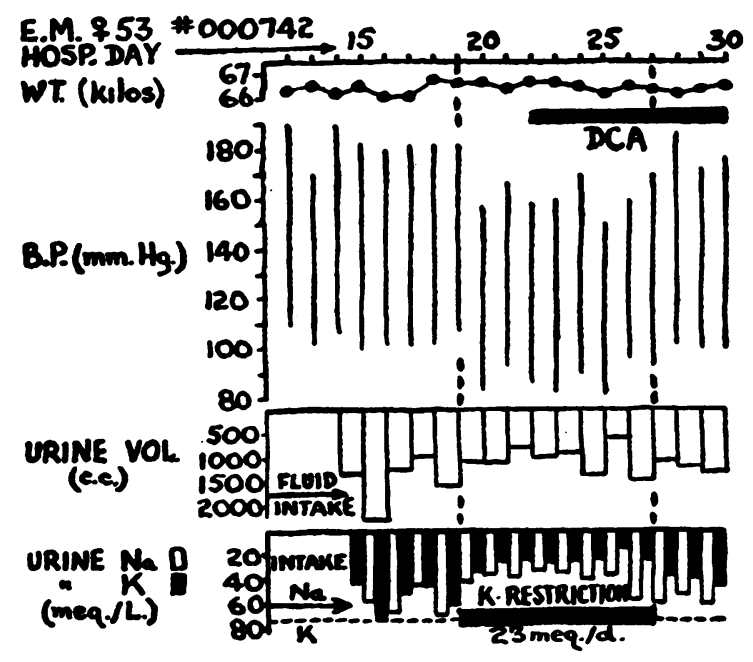

Fig. 1. Clinical and Laboratory Data of Hypertensive Patient Given Potassium-Deficient Diet 
TABLE I

Effects of potassium-eficient diets in hyperlensive subjects

\begin{tabular}{|c|c|c|c|c|c|c|c|c|c|c|c|c|c|}
\hline & \multirow{3}{*}{$\begin{array}{c}\begin{array}{c}\text { Diet; } \\
\text { duration } \\
\text { days }\end{array} \\
\begin{array}{c}\text { control } \\
(10)\end{array}\end{array}$} & \multirow{3}{*}{$\frac{\begin{array}{c}\mathrm{K} \\
\text { intake } \\
m E q . / d .\end{array}}{94}$} & \multicolumn{2}{|c|}{ “Resting” B.P. } & \multicolumn{3}{|c|}{ Urine (av./day) } & \multicolumn{4}{|c|}{ Serum } & \multirow[b]{2}{*}{$\begin{array}{l}\text { H'crit } \\
\text { \% cells }\end{array}$} & \multirow{2}{*}{$\begin{array}{c}\text { Weight } \\
\text { Start-End } \\
\text { kilos }\end{array}$} \\
\hline & & & Max. -Min. & Mean & $\begin{array}{l}\text { Vol. } \\
\text { cc. }\end{array}$ & $\underset{m E}{\mathrm{Na}}$ & & $\mathrm{Na}$ & & $\mathrm{Eq}_{\mathrm{Cl}}^{\mathrm{Cl}}$ & $\mathrm{CO}_{2}$ & & \\
\hline \multirow{2}{*}{ P. I. } & & & $\frac{176}{112}-\frac{166}{106}$ & $\frac{170}{108}$ & 2215 & 67 & 75 & 138 & 4.4 & 102 & 30.1 & 47 & \\
\hline & $\underset{(9)}{\operatorname{low} K}$ & 23 & $\frac{172}{102}-\frac{154}{92}$ & $\frac{164}{100}$ & 1998 & 41 & 52 & 141 & 4.1 & 102 & 31.5 & 46 & $74.4-74.0$ \\
\hline \multirow{4}{*}{ E. M. } & $\underset{(8)}{\text { control }}$ & 72 & $\frac{190}{110}-\frac{170}{100}$ & $\frac{182}{105}$ & 1472 & 60 & 58 & 137 & 4.1 & 102 & 27.1 & 36 & $66.4-66.6$ \\
\hline & $\underset{(3)}{\operatorname{low} K}$ & 23 & $\frac{166}{92}-\frac{158}{84}$ & $\frac{161}{87}$ & 1277 & 34 & 26 & 137 & 4.3 & 104 & 28.1 & 34 & $66.6-66.6$ \\
\hline & low $\underset{(5)}{\mathrm{K}}+\mathrm{DCA}$ & 23 & $\frac{170}{96}-\frac{150}{82}$ & $\frac{162}{89}$ & 1060 & 39 & 21 & 137 & 3.6 & 105 & 27.6 & 36 & $66.6-66.5$ \\
\hline & $\underset{(3)}{\text { control + DCA }}$ & 72 & $\frac{186}{102}-\frac{172}{100}$ & $\frac{178}{101}$ & 1147 & 57 & 39 & & & & & & $66.5-66.5$ \\
\hline \multirow{4}{*}{ L. $P$. } & $\underset{(5)}{\text { control }}$ & 67 & $\frac{180}{100}-\frac{170}{96}$ & $\frac{174}{99}$ & 1810 & 66 & 56 & 142 & 4.6 & 102 & 30.6 & & $67.4-67.0$ \\
\hline & $\underset{(3)}{\operatorname{low} K}$ & 21 & $\frac{166}{88}-\frac{164}{86}$ & $\frac{165}{87}$ & 1743 & 27 & 31 & 142 & 4.4 & & & & $67.0-66.9$ \\
\hline & $\operatorname{low}_{(4)} \mathrm{K}+\mathrm{DCA}$ & 21 & $\frac{174}{94}-\frac{154}{86}$ & $\frac{162}{88}$ & 1825 & 32 & 30 & 143 & 4.0 & 100 & 30.6 & & $66.9-67.9$ \\
\hline & $\underset{(4)}{\operatorname{control}+\mathrm{DCA}}$ & 67 & $\frac{178}{100}-\frac{164}{90}$ & $\frac{170}{96}$ & 1770 & 51 & 42 & & & & & & $67.9-68$ \\
\hline \multirow{4}{*}{ L. $P$. } & $\begin{array}{c}\text { control } \\
(5)\end{array}$ & 67 & $\frac{158}{90}-\frac{150}{86}$ & $\frac{153}{88}$ & 1973 & 65 & 57 & 143 & 4.4 & 102 & 30.0 & & $67.1-66.9$ \\
\hline & $\underset{(4)}{\operatorname{low} K}$ & 21 & $\frac{146}{86}-\frac{142}{80}$ & $\frac{143}{82}$ & $\cdot 1900$ & 31 & 32 & 142 & 4.2 & 100 & 28.0 & & $66.9-66.9$ \\
\hline & low $\underset{\mathrm{KCl}}{\mathrm{K}}+57 \mathrm{mEq}$ & - 78 & $\frac{164}{96}-\frac{160}{90}$ & $\frac{162}{93}$ & 2113 & 91 & 43 & & & & & & $66.9-66.2$ \\
\hline & $\begin{array}{c}\text { low } \mathrm{K} \\
(3)\end{array}$ & 21 & $\frac{158}{86}-\frac{154}{82}$ & $\frac{156}{84}$ & 2166 & 69 & 30 & & & & & & $66.2-65.9$ \\
\hline \multirow{3}{*}{ M. L. } & $\begin{array}{l}\text { control } \\
\text { (10) }\end{array}$ & 80 & $\frac{196}{120}-\frac{182}{114}$ & $\frac{189}{118}$ & 1570 & 71 & 63 & & & & & 45 & \\
\hline & $\underset{(8)}{\operatorname{low} K}$ & 20 & $\frac{176}{112}-\frac{156}{96}$ & $\frac{164}{103}$ & 1500 & 36 & 38 & & & & & 44 & \\
\hline & $\begin{array}{c}\text { control } \\
\text { (10) }\end{array}$ & 80 & $\frac{192}{116}-\frac{180}{110}$ & $\frac{185}{114}$ & 1510 & 68 & 58 & & & & & 44 & \\
\hline
\end{tabular}

"resting" blood pressure in every instance. This response appeared not later than 48 hours after diet modification and often within 24 hours, and the "resting" blood pressure rose promptly in those cases in which potassium chloride was added to the diet or when control diets were restored.

Curtailment of dietary potassium was followed by a decrease in the amount excreted in the urine, but in general these values remained larger than the intake with a resultant negative balance, perhaps reflected in the serum potassium concentrations which fell slightly in three of four studies. Urinary nitrogen determinations were made in one patient and showed a decrease in proportion to the 
reduced protein intake, thereby indicating that protein breakdown was contributing a negligible amount to the urinary potassium excreted during the limited period of these observations. In association with the restriction of potassium, urinary sodium excretion decreased sharply with an average positive balance, assuming other excretory routes were not invoked, of approximately $30 \mathrm{mEq}$. per day. Serum sodium concentrations, however, were not affected.

Except for a slight increase in constipation in two subjects, the restriction of potassium gave rise to no subjective distress. The shifts in electrolytes were unassociated with any major fluid alterations, at least as reflected in weight, hematocrit and urinary volume measurements, and in one subject the serum volume (calculated by means of the blue dye T. 1824) remained unaffected. Serum chloride and carbon dioxide content were not modified consistently. No patient was observed to develop urinary ketone bodies, and serum urea nitrogen values did not increase. Serial electrocardiograms and ballistocardiograms were obtained at frequent intervals in the course of two studies; the results were superimposable, nothing being found to suggest changes in cardiac function, intracardiac electrolyte alterations, or difference in the impact of the cardiac contraction.

In two instances, desoxycorticosterone acetate was administered while the patients were on the restricted diet. The "resting" blood pressure remained reduced until the control diet was resumed.

\section{DISCUSSION}

The decrease in "resting" blood pressure in response to short-term restriction of dietary potassium, observed six times in five studies on four patients with hypertensive vascular disease, confirms the reports of Freed, Friedman and Rosenman employing even greater restriction in hypertensive rats. It is noteworthy, with respect to the known therapeutic effects of salt restriction, that this phenomenon takes place despite rather marked sodium retention and, presumably, a rise in intracellular sodium (7-10).

The mechanism of the fall in blood pressure remains obscure. It appeared unrelated to serum volume changes in the one individual in whom measurements were made. It could not be ac- counted for by the decrease in protein intake, necessary to achieve the potassium restriction, for the initial degree of hypertension could be restored in one instance merely by the addition of potassium chloride; nor, incidentally, will protein supplementation alter the arterial tension when reduced by the "rice diet" (11). It is doubtful that the depressor effects can be related to loss of potassium from heart muscle and a resultant fall in cardiac output, although this possibility cannot be excluded completely; against such a mechanism are the rapidity of the blood pressure decrease, the absence of abnormally low serum potassium values, and the lack of alterations in the electro- and ballistocardiograms. With reference to the role of the adrenal cortex, one might presume that a high rather than a low potassium intake should be analogous to a low sodium regimen; nevertheless, the fact that a low potassium diet blocks the customary pressor response of hypertensives to desoxycorticosterone (12), also noted previously in the rat studies (4), makes it possible that the adrenal cortex is one of the areas requiring further consideration. Finally, it is possible that electrolyte imbalance exerts a direct effect on neuromuscular transmission and hence a direct effect on the physiological site of hypertension, the arterioles; marked sodium deficiency has been reported to give rise to a neuromuscular block and a reduced output of acetylcholine (13).

From these preliminary studies it cannot be concluded that potassium restriction is of therapeutic benefit. The diets employed were unpalatable and unbalanced, particularly with respect to protein. Had they been made more restrictive or continued for longer periods, signs and symptoms and dangerous cardiac complications might have been produced. These observations do serve, however, to point again to the relationship of certain cations to the hypertensive state-perhaps through the intervention of the adrenal cortex, but perhaps through some direct action on blood vessel walls.

\section{SUM MARY}

1. The restriction of dietary potassium, undertaken six times in four patients with hypertensive vascular disease, was followed rapidly by small but statistically significant decreases in "resting" blood pressure. 
2. Sodium retention accompanied the restriction of potassium.

3. The low potassium diet blocked the pressor response to desoxycorticosterone.

4. This study, confirming previous reports of hypotension observed in potassium-deficient rats, fails to exclude the possible participation of the adrenal cortex but is compatible also with the possibility of a direct role of cations upon neuromuscular transmission or upon blood vessel walls during the hypertensive state.

\section{ACKNOWLEDGMENTS}

The author acknowledges gratefully the assistance of Margaret Crymble, Iva Moen, Mary Iles and Margaret N. Hawthorne.

\section{REFERENCES}

1. Bacchus, H., Decrease of cardiac mass following excess dietary potassum chloride in the rat. Am. J. Physiol., 1951, 166, 273.

2. Freed, S. C., and Friedman, M., Hypotension in the rat following limitation of potassium intake. Science, 1950, 112, 788.

3. Freed, S. C., and Friedman, M., Depressor effect of potassium restriction on blood pressure of the rat. Proc. Soc. Exper. Biol. \& Med., 1951, 78, 74.

4. Rosenman, R. H., Freed, S. C., and Friedman, M., Effect of variation of potassium intake on pressor activity of desoxycorticosterone. Proc. Soc. Exper. Biol. \& Med., 1951, 78, 77.
5. Friedman, M., Freed, S. C., and Rosenman, R. H., Effect of potassium administration on (1) peripheral vascular reactivity and (2) blood pressure of the potassium-deficient rat. Circulation, 1952, 5, 415.

6. Perera, G. A., and Blood, D. W., The relationship of sodium chloride to hypertension. J. Clin. Invest., 1947, 26, 1109.

7. Darrow, D. C., Schwartz, R., Iannucci, J. F., and Coville, $F$., The relation of serum bicarbonate concentration to muscle composition. J. Clin. Invest., 1948, 27, 198.

8. Cooke, R. E., Segar, W. E., Cheek, D. B., Coville, F. E., and Darrow, D. C., The extrarenal correction of alkalosis associated with potassium deficiency. J. Clin. Invest., 1952, 31, 798.

9. Black, D. A. K., and Milne, M. D., Experimental potassium depletion in man. Lancet, 1952, 1, 244.

10. Fourman, P., and Ainley-Walker, K. M. S., Experimental depletion of potassium in man. Lancet, 1952, 2, 368.

11. Watkin, D. M., Froeb, H. F., Hatch, F. T., and Gutman, A. B., Effects of diet in essential hypertension. II. Results with unmodified Kempner rice diet in fifty hospitalized patients. Am. J. Med., 1950, 9, 441.

12. Perera, G. A., and Blood, D. W., Pressor activity of desoxycorticosterone acetate in normotensive and hypertensive subjects. Ann. Int. Med., 1947, 27. 401.

13. Fatt, P., and Katz, B., The effect of sodium ions on neuromuscular transmission. J. Physiol., 1952, 118, 73. 